\title{
A PLURIATIVIDADE COMO FATOR DE GERAÇÃO DE RENDA PARA A AGRICULTURA FAMILIAR DE CÓRREGO PRIMAVERA, RIO BANANAL, ESPÍRITO SANTO, BRASIL
}

\author{
Rôner de Souza Fernandes ${ }^{1}$ \\ Alessandra Maria da Silva ${ }^{2}$ \\ Rayane Pagung Falcão ${ }^{3}$
}

\section{RESUMO}

Este trabalho teve por objetivo analisar a pluriatividade como atividade geradora de renda na agricultura familiar da Comunidade Córrego Primavera, município de Rio Bananal, norte do estado do Espirito Santo. Para tanto, foi realizada uma pesquisa de campo adotando-se uma abordagem qualitativa com entrevista semiestruturada para 19 famílias pluriativas residentes na Comunidade Córrego Primavera, durante os meses de julho a outubro de 2016. Os resultados das entrevistas foram submetidos à análise de conteúdo. As principais atividades não agrícolas observadas entre as famílias estudadas se enquadram como intersetoriais, sendo a de serviços a mais frequente. Observou-se que os principais fatores motivadores da pluriatividade apontados pelas famílias estudadas foram a necessidade de geração de renda extra e de ocupação da mão de obra ociosa. As famílias demonstraram não ter conhecimentos administrativos e de custo de produção das atividades desenvolvidas. Concluiu-se que a pluriatividade é um fator importante para a estratégia de reprodução econômica das famílias rurais e que há a necessidade de conscientização de seus membros para a eficiência na gestão de recursos humanos e materiais.

Palavras-chave: estratégias de reprodução econômica, gestão de recursos da família, ocupações não agrícolas, renda.

\section{THE PLURIATIVITY AS A FACTOR OF GENERATION OF INCOME FOR FAMILY FARMING OF CÓRREGO PRIMAVERA, RIO BANANAL, ESPÍRITO SANTO, BRAZIL}

\begin{abstract}
The objective of this study was to analyze pluriactivity as an income - generating activity in family agriculture of the Córrego Primavera Community in the municipality of Rio Bananal, Espírito Santo, Brazil. For that, a field research was carried out adopting a qualitative approach with a semi-structured interview for 19 family farms living in the

\footnotetext{
${ }^{1}$ Graduado em Administração (FACELI). E-mail: ronersf@gmail.com

2 Graduada em Medicina Veterinária (UFV). Especialista em Gestão Pública (IFES). Mestre em Medicina Veterinária (UFV). Doutoranda em Produção Vegetal (UENF). Agente de Extensão em Desenvolvimento Rural do Instituto Capixaba de Pesquisa e Extensão Rural (INCAPER). E-mail: alessandra@incaper.es.gov.br

${ }^{3}$ Graduada em Administração (FACELI). E-mail: rayane-falcao@hotmail.com
} 
Córrego Primavera Community, from July to October 2016. The results of the interviews were submitted to content analysis. The main non-agricultural activities observed among the studied families are classified as intersectoral, with services being the most frequent. It was observed that the main factors motivating the pluriactivity indicated by the families studied were the need to generate extra income and to occupy the idle labor force. The families demonstrated that they did not have administrative knowledge and the cost of production of the activities developed. It was concluded that pluriactivity is an important factor for the strategy of economic reproduction of rural families and that there is a need for awareness of its members for efficiency in the management of human and material resources.

Key words: income; management of family resources; non-agricultural occupations; strategies for economic reproduction.

\section{INTRODUÇÃO}

Nos últimos trinta anos, a agricultura familiar tem sido alvo de pesquisas acadêmicas e ponto central nas agendas das políticas públicas para 0 desenvolvimento rural, dada a sua importância econômica e social no processo de transformações estruturais do espaço rural no Brasil. Após o período da Modernização da Agricultura, contemporâneo ao período da ditadura militar no Brasil, o qual foi acompanhado de intensificações nas desigualdades sociais, especialmente no campo, e de expressivo êxodo rural, a agricultura familiar emergiu como um setor de grande importância para o desenvolvimento rural. A capacidade da agricultura familiar em resistir às pressões capitalistas impostas pelo agronegócio globalizado chamou a atenção do meio acadêmico que passou a pesquisar as estratégias de reprodução social adotadas pelas famílias rurais. Assim, a pluriatividade tem se revelado como uma das principais alternativas desenvolvidas pela agricultura familiar, especialmente no que se refere às ocupações não agrícolas.

Nesse sentido, o debate sobre a contribuição da pluriatividade na agricultura familiar para o desenvolvimento rural se volta para a capacidade das famílias rurais pluriativas em aproveitar as oportunidades sociais e econômicas para sua resistência e permanência no campo. As formas de articulação entre a agricultura familiar pluriativa e o mercado são diversificadas e dependem de externalidades, como as condições ambientais e econômicas do meio em que vive, bem como da presença do Estado por meio de políticas públicas, as quais influenciam nas decisões sobre as estratégias familiares dos agricultores.

A Microrregião Rio Doce, localizada ao Norte do Estado do Espírito Santo, tem apresentado crescimento econômico regional por meio da implantação de indústrias diversas na última década, as quais têm ocupado o espaço rural em um claro processo de descentralização industrial. Outras mudanças estruturais que ocorrem na região, como relações de mercado e aumento da demanda por serviços urbanos, podem contribuir para a alteração no comportamento da gestão dos recursos produtivos e humanos pelos agricultores familiares ali residentes, que tendem a se tornar pluriativos.

O município de Rio Bananal está inserido nessa Microrregião. Sua população, segundo o Instituto Brasileiro de Geografia e Estatística - IBGE (2010), é predominantemente rural, sendo que $62 \%$ do total da população reside no campo. No entanto, a modernização dos meios de comunicação e de transporte no interior do município, que ocorreu especialmente a partir do início dos anos 2000, tem facilitado a integração do espaço urbano com o espaço rural. Isso pode influenciar na 
mobilidade e no acesso da população rural aos serviços, comércio e ao mercado de trabalho urbano, contribuindo para o desenvolvimento da pluriatividade em Rio Bananal, especialmente nas localidades mais próximas do perímetro urbano. A pluriatividade pode, dessa forma, representar uma estratégia importante de reprodução das famílias rurais daquele município

O objetivo deste trabalho foi analisar a pluriatividade como atividade geradora de renda para a agricultura familiar da Comunidade de Córrego Primavera, município de Rio Bananal, Espírito Santo.

\section{METODOLOGIA}

Para se alcançar o objetivo proposto foi aplicada a pesquisa do tipo qualitativa. O recorte do objeto de estudo foram as famílias agricultoras residentes na comunidade Córrego Primavera, localizada a $4 \mathrm{~km}$ da sede do município de Rio Bananal, Norte do Estado do Espírito Santo, que se enquadraram no critério de "agricultura familiar" proposto pela Lei $n^{\circ} 11.326$, de 24 de julho de 2006 (BRASIL, 2006) e que apresentaram a pluriatividade como estratégia de reprodução. A pesquisa foi realizada no período de julho a outubro de 2016.

A avaliação da geração de renda das atividades agrícolas e não agrícolas, bem como o conhecimento do processo de gestão de recursos nas propriedades agrícolas da Comunidade de Córrego Primavera foi realizada por meio de análise de dados levantados pela aplicação de entrevistas semiestruturadas a um dos membros das famílias participantes da amostra. Foram levantadas as principais atividades desenvolvidas, sua importância na geração de renda, quem são os membros da família economicamente ativos e suas respectivas atividades, como se dá o processo de decisão nas escolhas das atividades agrícolas e não agrícolas, bem como o processo de planejamento e gestão dos recursos financeiros.

Devido ao longo período de estiagem que ocorreu na região entre os anos de 2014 a 2016, comprometendo a produtividade das lavouras, os dados referentes à produção das atividades agrícolas foram coletados com base na produção média entre os anos de 2014, 2015 e 2016. O cálculo da renda bruta se deu pela conversão da produção média em valores monetários praticados no mercado atual, conforme o "Acompanhamento Semanal de Preços Recebidos pelos Produtores", considerando a média mensal dos preços médios praticados no mês de referência outubro de 2016 , obtido junto ao Instituto Capixaba de Pesquisa, Assistência Técnica e Extensão Rural (INCAPER, 2016).

As informações prestadas com relação à produção e renda foram auto declaratórias, não sendo possível sua confirmação. Portanto, os valores obtidos foram aproximados e considerados para efeito de proporção na renda total e de importância para a reprodução familiar, aliando-se às percepções dos entrevistados.

Foram entrevistados sujeitos representantes de vinte e duas famílias agricultoras selecionadas pela técnica de "Bola de Neve". De acordo com Dewes (2013), a amostragem em "Bola de Neve" é um método utilizado em populações desconhecidas - como é o caso deste estudo -, e quando construir uma listagem completa seria difícil, oneroso ou impraticável. Esta técnica deve ser utilizada quando se pressupõe uma ligação entre os membros da população dada pela característica de interesse, ou seja, os membros da população são capazes de identificar outros membros com o mesmo perfil.

A técnica de "Bola de Neve" se baseia em um informante inicial que indica potenciais unidades de análise. Neste trabalho o informante foi um representante do Sindicato dos Trabalhadores Rurais de Rio Bananal (STRRB), que forneceu uma relação de dez famílias pluriativas residentes na comunidade em questão. De posse 
da relação de famílias, foi realizado um sorteio para seleção da primeira unidade de análise e, a partir dela, outra unidade foi indicada pela família e assim sucessivamente, até se atingir o total da amostra (DEWES, 2013).

O tamanho da amostra se deu por saturação empírica. Considerou-se como saturação empírica quando o campo de pesquisa não mais forneceu novos elementos que balizassem ou aprofundassem a teorização, conforme sugerido por Fontanella et al. (2011). A identidade dos representantes familiares entrevistados foi preservada. Para efeito de identificação das famílias, adotou-se a codificação AF para agricultores familiares, seguida da numeração da ordem em que foram entrevistados. Sendo assim, os códigos variaram de AF1 até AF22. Das vinte e duas entrevistas coletadas, três foram excluídas do processo de análise, por não representarem agricultores familiares, após verificação da proporção de renda e de área da propriedade. Assim, foram mantidas dezenove famílias para análise dos dados.

Todas as entrevistas foram gravadas, transcritas, codificadas, sistematizadas e submetidas à análise de conteúdo (BARDIN, 1977). A categorização das entrevistas foi feita a posteriori, baseando-se nos critérios de proporção e origem da renda, escolaridade, atividades tipificadas, motivação, processo decisório, gestão de recursos humanos e da renda.

\section{RESULTADOS E DISCUSSÃO}

\subsection{O MUNICÍPIO DE RIO BANANAL NO CONTEXTO DA AGRICULTURA FAMILIAR}

O município de Rio Bananal está inserido na Microrregião Administrativa do Rio Doce, norte do Estado do Espírito Santo e apresenta Índice de Desenvolvimento Humano (IDH) municipal de 0,681. Possui uma área de $642.229 \mathrm{~km}^{2}$ e uma população residente de 17.530 pessoas. Sua economia se baseia principalmente em serviços e na agropecuária, representando 56,6\% e 32,7\% do Produto Interno Bruto (PIB) municipal, respectivamente. A principal ocupação do solo se dá pelo cultivo de café Conilon e frutas. A agricultura emprega $69,3 \%$ da população economicamente ativa masculina e $48,8 \%$ da população feminina (IBGE, 2010).

Constituída por apenas dois distritos (Sede e São Jorge de Tiradentes), a maior parte da população ribanense reside na área rural do município, correspondendo a $61 \%$ da população total (IBGE, 2010). De acordo com a série histórica estatística do Censo Demográfico 2010 (IBGE, 2010), em 1990 o município de Rio Bananal possuía mais de $80 \%$ da sua população residente no espaço rural. Essa redução da população rural pode ser devida ao êxodo rural recorrente em todos os municípios brasileiros, mas também pela própria percepção do que é rural e do que é urbano para a metodologia do Instituto Brasileiro de Geografia e Estatísticas (IBGE), que considera aglomerados rurais, como as sedes distritais, como área urbana.

De acordo com Wanderley (2000) e Graziano da Silva (1997), há uma crescente dificuldade em se separar o urbano do rural, havendo um continuum entre ambos, no qual valores e hábitos urbanos se inseriram no rural e o urbano depende do rural para seu desenvolvimento. O espaço rural não pode ser visto separado do urbano, em especial em sua economia pluriativa. Esse fator é evidenciado no Município de Rio Bananal, onde sua população reside principalmente no espaço rural, enquanto a sua economia depende prioritariamente do setor terciário, seguido do setor primário.

O Censo Agropecuário de 2006 do IBGE apresentou a existência de 1.505 propriedades no município de Rio Bananal (Tabela 1) que ocupam uma área de 43.518 ha, sendo 1.176 estabelecimentos pertencentes a agricultura familiar, 
correspondendo a $79,9 \%$ dos estabelecimentos, que ocupam $49,6 \%$ da área produtiva (IBGE, 2006) e empregando 4.089 pessoas, diretamente (BRASIL, 2015).

Tabela 1 - Caracterização fundiária do município de Rio Bananal-ES quanto ao número de propriedades e área ocupada

\begin{tabular}{lrr}
\hline Propriedades & № total & Área ocupada (ha) \\
\hline Agricultura & & \\
Familiar & 1.176 & 21.584 \\
Outros & 329 & 21.934 \\
Total & $\mathbf{1 . 5 0 5}$ & $\mathbf{4 3 . 5 1 8}$ \\
\hline \multicolumn{2}{r}{ Fonte: elaborado a partir dos dados do IBGE (2006). }
\end{tabular}

As principais atividades agrícolas desenvolvidas no município de Rio Bananal, baseadas em área ocupada e de acordo com os dados do IBGE (2015), são: cafeicultura (café Conilon), lavouras temporárias como milho e feijão, pipericultura (cultivo de pimenta-do-reino) e fruticultura (Tabela 2). Com relação à produção pecuária, o município apresenta como principais atividades a bovinocultura leiteira, a suinocultura e a avicultura de base familiar (Tabela 3 ).

Tabela 2 - Principais atividades agrícolas do município de Rio Bananal-ES, por área ocupada, em ha, em 2015

\begin{tabular}{lr}
\hline \multicolumn{1}{c}{ Atividade Agrícola } & Área ocupada (ha) \\
\hline Café Conilon (Coffea & 13.800 \\
canephora) & 400 \\
Feijão & 250 \\
Milho & 180 \\
Coco-da-baía & 127 \\
Cacau & 100 \\
Pimenta-do-reino & 80 \\
Banana & 60 \\
Mandioca & 50 \\
Cana-de-açúcar & 30 \\
Maracujá & 15 \\
Seringueira & \\
\hline
\end{tabular}

Fonte: elaborado a partir dos dados do IBGE, Produção Agrícola Municipal 2015. 
Tabela 3 - Efetivos dos rebanhos e produção pecuária no município de Rio BananalES, em 2015

\begin{tabular}{lcc}
\hline \multicolumn{1}{c}{ Efetivo dos rebanhos } & Quantidade & Unidade \\
\hline Bovinos & 10.280 & Cabeças \\
Suínos & 4.800 & Cabeças \\
Galináceos & 41.000 & Cabeças \\
\hline \multicolumn{1}{c}{ Produção anual } & & \\
\hline Leite de vaca & 1.150 & Mil litros \\
Ovos de galinha & 71 & Mil dúzias \\
Mel de abelha & 10.000 & kg \\
\hline Fonte: elaborado a partir dos dados do IBGE, Produção da Pecuária Municipal 2015.
\end{tabular}

Com relação à pluriatividade, o INCAPER divulgou em seu documento PROATER (Programa de Assistência Técnica e Extensão Rural) de 2011 a existência de atividades não agrícolas como agroindústrias (queijarias, processamento de frutas), artesanato, fabricação de móveis, dentre outras, desenvolvidas no município de Rio Bananal (INCAPER, 2011).

\subsection{CARACTERIZAÇÃO DOS SUJEITOS DA AMOSTRA}

As dezenove famílias participantes da pesquisa são compostas por, em média, 3,8 membros, variando de três a oito moradores em cada propriedade. O grau de escolaridade observado entre os membros em idade potencialmente ativa varia de ensino fundamental incompleto (séries iniciais) até pós-graduação. Esse fator demonstra uma certa heterogeneidade quanto à escolarização da amostra estudada.

Todas as famílias residem em Córrego Primavera, detendo propriedades que variam de minifúndios a pequenas propriedades, conforme a classificação dos imóveis rurais proposta pelo Instituto Nacional de Colonização e Reforma Agrária - INCRA (2016). A classificação proposta pelo INCRA leva em conta o módulo fiscal - que em Rio Bananal é de 20 ha - e é definida pela Lei 8.629, de 25 de fevereiro de 1993: minifúndio, inferior a um módulo fiscal; pequena propriedade, entre um e quatro módulos fiscais; média propriedade, superior a quatro e até quinze módulos fiscais; grande propriedade, superior a quinze módulos fiscais. O tamanho médio das propriedades foi 16 ha (Quadro 1), variando de 2,5 a 50 ha, com predominância de minifúndios (63\% das famílias participantes).

A renda das famílias entrevistadas é oriunda, basicamente, das atividades agrícolas e das ocupações não agrícolas. Apenas duas famílias possuem renda oriunda de aposentadoria e de aluguel de imóvel (AF2 e AF3). Observa-se, na Tabela 4, que a proporção da renda oriunda das ocupações não agrícolas varia consideravelmente (de $6 \%$ a $70 \%$ ) entre as famílias entrevistadas, tendo, portanto, graus de importância na reprodução familiar também diferentes. A importância da renda da pluriatividade será discutida posteriormente. 
Quadro 1 - Caracterização das propriedades das famílias pluriativas estudadas em Córrego Primavera, Rio Bananal-ES, em relação ao tamanho, condições de posse e atividades agrícolas, 2016

\begin{tabular}{|c|c|c|c|}
\hline Família & $\begin{array}{c}\text { Tamanho da } \\
\text { propriedade } \\
\text { (ha) }\end{array}$ & $\begin{array}{c}\text { Condição de } \\
\text { posse }\end{array}$ & $\begin{array}{c}\text { Atividades agrícolas } \\
\text { desenvolvidas }\end{array}$ \\
\hline AF1 & 25 & Proprietário & Café e pimenta \\
\hline AF2 & 25 & Meeiro & Café, pimenta, coco e cacau \\
\hline AF3 & 17 & Proprietário & Cacau, banana e laranja \\
\hline AF4 & 4 & $\begin{array}{c}\text { Proprietário } \\
\text { meeiro }\end{array}$ & Café, pimenta e cacau \\
\hline AF6 & 2,5 & Proprietário & Café, pimenta, coco e cacau \\
\hline AF7 & 40 & Proprietário & Café, pimenta, coco e cacau \\
\hline AF9 & 4 & Proprietário & Café, pimenta, coco e cacau \\
\hline AF10 & 15 & Proprietário & Café e pimenta \\
\hline AF11 & 5 & Proprietário & Café, coco, cacau e fibra \\
\hline AF12 & 50 & Proprietário & Café, pimenta e leite \\
\hline AF13 & 2,5 & Proprietário & Café, pimenta, banana e aipim \\
\hline AF14 & 3 & Proprietário & Café e pimenta \\
\hline AF15 & 25 & Proprietário & Café \\
\hline AF16 & 30 & Proprietário & Café, pimenta, coco e cacau \\
\hline AF18 & 23 & Proprietário & Café, abóbora e eucalipto \\
\hline AF19 & 15 & Proprietário & Café, pimenta e cacau \\
\hline AF20 & 12 & Proprietário & Café e pimenta \\
\hline AF21 & 2,5 & Proprietário & Café e pimenta \\
\hline AF22 & 2,5 & Proprietário & Café \\
\hline
\end{tabular}

Fonte: elaborado pelos autores

Para o enquadramento das famílias como agricultoras familiares, todas aquelas que permaneceram na amostra atenderam aos critérios de tamanho da propriedade, gestão familiar, mão de obra predominantemente familiar e renda. A renda bruta anual média das famílias foi em torno de $R \$ 99.800,00$, sendo a renda oriunda da agropecuária em torno de $\mathrm{R} \$ 71.400,00$, em média. A proporção média da renda agrícola foi de $65 \%$ sobre a renda bruta total. Para efeitos de enquadramento como agricultor familiar, conforme a Lei 11.326/2006, a renda principal deve ser oriunda da agropecuária, incluindo as rendas para-agrícolas, como o processamento de alimentos produzidos na propriedade e artesanatos. Sob essa análise, as famílias AF6, AF14, AF19 e AF22 não se enquadrariam nos critérios de proporção de renda. No entanto, há de se observar que a renda agrícola é flutuante, modificando-se de acordo com as variações climáticas e de mercado. Em condições climáticas normais, provavelmente, essas famílias se enquadrariam nos critérios de proporção de renda. Daí a decisão de mantê-las na análise deste estudo, haja vista que atendem a todos os demais critérios de enquadramento. 
Tabela 4 - Fontes de renda das famílias agricultoras pesquisadas do Córrego Primavera, Rio Bananal-ES, 2016

\begin{tabular}{|c|c|c|c|c|c|c|c|}
\hline \multirow{3}{*}{ Família } & \multicolumn{6}{|c|}{ Renda Bruta Anual (R\$) } & \multirow{3}{*}{$\begin{array}{c}\% \\
\text { ONA }^{\star \star}\end{array}$} \\
\hline & \multirow[b]{2}{*}{ Agrícola } & \multicolumn{3}{|c|}{ Pluriatividade } & \multirow[b]{2}{*}{ Outros* } & \multirow[b]{2}{*}{ Total } & \\
\hline & & $\begin{array}{c}\text { Para } \\
\text { agrícola }\end{array}$ & $\begin{array}{c}\text { Base } \\
\text { agrícola }\end{array}$ & Intersetorial & & & \\
\hline $\mathrm{AF} 1$ & $56.804,56$ & & & $12.350,00$ & & $69.154,56$ & 17,9 \\
\hline AF2 & $37.383,99$ & & & $13.000,00$ & $11.440,00$ & $61.823,99$ & 21,0 \\
\hline AF3 & $4.032,00$ & $3.600,00$ & & & $7.200,00$ & $14.832,00$ & 24,3 \\
\hline AF4 & $35.774,09$ & & & $28.940,00$ & & $64.714,09$ & 44,7 \\
\hline AF6 & $13.170,80$ & & & $19.200,00$ & & $32.370,80$ & 59,3 \\
\hline AF7 & $460.888,49$ & $5.400,00$ & & $29.900,00$ & & $496.188,49$ & 7,1 \\
\hline AF9 & $17.937,40$ & & & $16.900,00$ & & $34.837,40$ & 48,5 \\
\hline AF10 & $15.477,99$ & & & $6.840,00$ & & $22.317,99$ & 30,6 \\
\hline AF11 & $44.465,61$ & $6.000,00$ & & $11.440,00$ & & $61.905,61$ & 28,2 \\
\hline AF12 & $197.777,59$ & $11.520,00$ & & & & $209.297,59$ & 5,5 \\
\hline AF13 & $45.964,94$ & & & $43.000,00$ & & $88.964,94$ & 48,3 \\
\hline AF14 & $13.132,84$ & & $24.000,00$ & $2.400,00$ & & $39.532,84$ & 66,8 \\
\hline AF15 & $28.141,80$ & & & $26.400,00$ & & $54.541,80$ & 48,4 \\
\hline AF16 & $122.315,00$ & & & $13.200,00$ & & $135.515,00$ & 9,7 \\
\hline AF18 & $66.602,26$ & & & $20.800,00$ & & $87.402,26$ & 23,8 \\
\hline AF19 & $75.481,00$ & & $150.000,00$ & $24.000,00$ & & $249.481,00$ & 69,7 \\
\hline AF20 & $67.071,29$ & & & $5.280,00$ & & $72.351,29$ & 7,3 \\
\hline AF21 & $45.964,92$ & & & $33.800,00$ & & $79.764,92$ & 42,4 \\
\hline AF22 & $8.442,40$ & & & $13.000,00$ & & $21.442,40$ & 60,6 \\
\hline
\end{tabular}

* Aposentadoria ou aluguel de imóveis.

** Proporção da participação da renda oriunda de Ocupações Não Agrícolas na renda total familiar.

Fonte: elaborado pelos autores

\subsection{PRINCIPAIS ATIVIDADES AGRÍCOLAS E NÃO AGRÍCOLAS DESENVOLVIDAS PELAS FAMÍLIAS AGRICULTORAS DE CÓRREGO PRIMAVERA}

Conforme especificado no Quadro 1, as principais atividades agrícolas desenvolvidas pelas famílias entrevistadas foram: café, pimenta-do-reino, cacau e coco. Das 19 famílias estudadas, 18 exerciam como principal atividade agrícola a cafeicultura, 14 desenvolviam a pipericultura. Destas, 12 exerciam até três atividades agrícolas (Quadro 1). Esse fator demonstra a relativa baixa diversificação produtiva nas propriedades rurais. Considerando-se que as principais atividades desenvolvidas por estes agricultores são atividades perenes e sazonais, a renda agrícola se concentra em determinados períodos do ano, bem como o emprego da mão de obra nos tratos culturais.

As atividades não agrícolas desenvolvidas pelas famílias estudadas se resumem no Quadro 2, conforme tipificação proposta por Schneider (2007). Observase que as atividades estão distribuídas nos diversos tipos, concentrando-se, especialmente, no intersetorial. Foram identificadas apenas duas famílias que desenvolvem atividades de base agrária, sendo que ambas atuam como intermediárias no comércio informal de coco na região. 
Quadro 2 - Número de membros das famílias estudadas envolvidos na pluriatividade do Córrego Primavera, Rio Bananal-ES, e as respectivas Ocupações não Agrícolas (ONA) de acordo com a tipificação proposta por Schneider (2007), em 2016

\begin{tabular}{|c|c|c|l|l|l|}
\hline \multirow{2}{*}{ Famílias } & \multicolumn{2}{|c|}{$\begin{array}{c}\text { Número de } \\
\text { membros }\end{array}$} & \multicolumn{3}{c|}{ Ocupações Não Agrícolas (ONA) } \\
\cline { 2 - 6 } & Total & $\begin{array}{c}\text { Em } \\
\text { ONA }\end{array}$ & Para-agrícola & Base agrária & \multicolumn{1}{|c|}{ Intersetorial } \\
\hline AF1 & 3 & 1 & & & Serviços \\
\hline AF2 & 3 & 1 & & & Comércio \\
\hline AF3 & 5 & 1 & Agroindústria & & Comércio/Serviços \\
\hline AF4 & 8 & 3 & Artesanato & & Serviços \\
\hline AF6 & 3 & 1 & & & Serviços \\
\hline AF7 & 5 & 2 & Agroindústria & & Serviços \\
\hline AF9 & 4 & 1 & & & Serviços \\
\hline AF10 & 4 & 2 & & & Serviços \\
\hline AF11 & 3 & 2 & Artesanato & & Serviços \\
\hline AF12 & 3 & 1 & Agroindústria & & Serviços \\
\hline AF13 & 5 & 2 & & & Serviços \\
\hline AF14 & 3 & 2 & Artesanato & Comércio de coco & Serviços/Indústria \\
\hline AF15 & 3 & 1 & & & Serviços \\
\hline AF16 & 4 & 1 & & & Serviços \\
\hline AF18 & 3 & 2 & & & Comércio/Serviços/ \\
\hline AF19 & 3 & 2 & & & Indústria \\
\hline AF20 & 3 & 1 & & & Serviços \\
\hline AF21 & 5 & 2 & & & \\
\hline AF22 & 3 & 1 & & & \\
\hline
\end{tabular}

Fonte: elaborado pelos autores a partir dos dados empíricos.

Em seus estudos, Schneider e Conterato (2006) observaram que em unidades familiares monoativas (que desenvolvem somente atividades agropecuárias), especialmente naquelas que desenvolvem atividades sazonais, há uma grande dependência da renda anual, expondo-as aos imperativos climáticos e de mercado, desvelando a fragilidade dessas famílias e tornando-as reféns da única fonte de renda.

De fato, o município de Rio Bananal enfrentou nos últimos dois anos-safra intempéries climáticas que sacrificaram a produção agropecuária. De 2014 a 2016, a falta de chuvas na região norte do Estado, com médias de precipitação inferiores à média histórica, resultou em perdas significativas na produção. De acordo com os dados levantados em 2016 pelo Governo do Estado do Espírito Santo, a redução da produção agrícola superou a $30 \%$. Especialmente com relação à cafeicultura (café Conilon), a queda na produção foi de $40 \%$ em todo o Estado (ESPÍRITO SANTO, 2016).

A crise hídrica foi uma queixa comum entre as famílias entrevistadas. Diversas famílias reclamaram da perda na produção de café e de pimenta-do-reino, especialmente.

Esse ano deu bem menos. $O$ ano passado deu umas 80 sacas. Esse ano não deu nem um terço. Esse ano, por falta d'água, caiu tudo. Tava carregando os pés [de pimenta], a coisa mais linda... Caiu tudo! (AF1).

[O café] dessa vez agora, estava esperando de 100 a 120 sacas. Deu 16 por causa da seca, né? [...] Morreu bastante [pimenta] porque faltou água e eu tive que replantar (AF9). 
Embora as intempéries climáticas possam ser consideradas como fator motivador da decisão pelo exercício da pluriatividade pelas famílias agricultoras de Rio Bananal, somente a família do entrevistado AF3 tornou-se pluriativa em decorrência das consequências da crise hídrica que a região tem enfrentado nos últimos anos. Todos os demais já exerciam a atividade anteriormente a esse período. Mas, não se pode negar que todos os entrevistados reconheceram a importância da pluriatividade como uma forma de diversificação da renda familiar para o enfrentamento dos momentos de privações, sejam eles em decorrência das intempéries climáticas, sejam em decorrência de períodos de retração do mercado.

O que levou [a ingressar na pluriatividade] foi o caso a banana parou de produzir [devido à seca]. Aí, tinha que ter mais alguma coisa para ajudar na renda, né? (AF3).

Nossa, ajuda a gente muito! Deus me livre! Principalmente este ano, que não deu café. É um dinheiro que vem ajudar na hora da precisão (AF10).

A gente precisa, né? Porque só do café não dá. O café que a gente tem, colhe é pouco, aí tem que trabalhar pra manter a casa, manter as crianças. Porque uma pessoa sozinha não dá conta de manter tudo. Só se a pessoa tiver uma grande quantidade de terra, muita coisa. Agora a gente, assim, que é pequeno proprietário, é difícil um só pra manter, ainda mais nessa crise que tá aí agora (AF13).

Observando o Quadro 3, tem-se que a principal atividade intersetorial desenvolvida foi a de serviços, executadas no centro urbano, especialmente. Dentre os serviços, destacam-se a função de professora e comerciário. Observa-se que, para as atividades para-agrícolas, predomina a produção artesanal de alimentos, seguida de bordados e produção artesanal de vassouras. Na pluriatividade intersetorial há um maior número de pessoas envolvidas no setor de serviços, especialmente aqueles vinculados ao espaço urbano.

Mussato e Santos (2014) observaram que a proximidade com a cidade e a facilidade no acesso são fatores que contribuíram para a ocorrência de casos de pluriatividade na agricultura familiar do município de Itapejara d'Oeste-PR, cujas características fundiárias se assemelham às de Rio Bananal. Pode-se, portanto, considerar que a distância não seria um fator limitador para o desenvolvimento da pluriatividade em Rio Bananal, mas que, também, a proximidade dos centros urbanos seria uma facilidade a mais para as famílias, contribuindo para a tomada de decisão, especialmente para as atividades intersetoriais. Provavelmente, as atividades de base agrária e para-agrícolas se concentrem nas comunidades mais distantes. Esta hipótese poderá ser confirmada em trabalhos futuros.

Da mesma forma como encontrado neste trabalho, Schneider e Conterato (2006) observaram que no Rio Grande do Sul predomina a pluriatividade intersetorial, especialmente na Serra Gaúcha, onde há um polo calçadista. Eles atribuem a predominância da intersetorialidade ou de base agrária de acordo com os contextos e relações espaciais e de mercado de cada região. Esses autores afirmam que a intersetorialidade vinculada ao espaço urbano é uma forma de permitir que indivíduos que habitam o meio rural busquem emprego no espaço urbano sem haver a necessidade de se estabelecer fluxos migratórios. 
Quadro 3 - Principais tipos de pluriatividade desenvolvidos pelas famílias agricultoras estudadas da Comunidade Córrego Primavera, Rio Bananal-ES, em 2016

\begin{tabular}{|c|c|c|c|c|}
\hline \multicolumn{5}{|c|}{ Tipos de Pluriatividade } \\
\hline \multirow{2}{*}{ Para-agrícola } & \multirow{2}{*}{ Base agrária } & \multicolumn{3}{|c|}{ Intersetorial } \\
\hline & & Serviços & Comércio & Indústria \\
\hline $\begin{array}{l}\text { Artesanato } \\
\text { (confecção de } \\
\text { vassouras, } \\
\text { bordados) } \\
\text { agroindústrias } \\
\text { artesanais } \\
\text { (produção de } \\
\text { queijo, produção } \\
\text { de pães, bolos, } \\
\text { doces) }\end{array}$ & Comércio de coco & $\begin{array}{l}\text { Pedreiro, motorista } \\
\text { de ambulância, } \\
\text { motorista de } \\
\text { transporte escolar, } \\
\text { arquiteto, instrutor } \\
\text { de autoescola, } \\
\text { doméstica, faxineira, } \\
\text { babá, professora, } \\
\text { merendeira, } \\
\text { recepcionista }\end{array}$ & $\begin{array}{l}\text { Proprietário de bar, } \\
\text { comerciário }\end{array}$ & $\begin{array}{l}\text { Proprietário de } \\
\text { serralheria, } \\
\text { proprietário de } \\
\text { fábrica de blocos }\end{array}$ \\
\hline
\end{tabular}

Fonte: elaborado pelos autores

Giannakis; Efstratoglou e Antoniades (2018) concluíram que a pluriatividade é mais predominante em locais cuja estrutura do mercado de trabalho - com maior participação dos setores de indústrias e de serviços - e de educação são mais desenvolvidos, pois a facilidade de acesso tende a moldar a propensão dos agricultores a trabalharem em atividades não agrícolas.

Observa-se, também, que o número de pessoas envolvidas em ocupações não agrícolas em cada família, variou de uma a três, indicando que a busca por outras formas de renda e trabalho não está destinada a apenas um dos membros da família, mas pode ser desempenhada por todos os membros economicamente ativos. No entanto, o predomínio de atividades que resultam em baixa remuneração torna-se preocupante no que condiz à proletarização da mão de obra familiar, conforme observado por Schneider (2007) e representado no Quadro 3.

\subsection{PRINCIPAIS FATORES MOTIVADORES DA PLURIATIVIDADE}

\section{a) Ocupação da mão de obra ociosa}

A geração de renda e a empregabilidade da mão de obra ociosa foi um dos principais motivos para o desenvolvimento da pluriatividade nas propriedades familiares rurais. Vale destacar que, em relação à empregabilidade da mão de obra ociosa foram apresentados como causas: o tamanho reduzido da propriedade familiar, que influenciaria na limitação de espaço de produção e, consequentemente, no montante de tarefas, ocupando apenas parte dos membros das famílias, deixando outros ociosos; a mecanização da agricultura, reduzindo-se a necessidade de mão de obra, gerando a agricultura de tempo parcial; e a predominância da cafeicultura no município, cuja concentração de trabalho é sazonal, liberando os agricultores por um período do ano para o exercício de outras atividades, sendo também uma agricultura de tempo parcial (GRAZIANO DA SILVA, 1997; SCHNEIDER, 2010).

Schneider, Ferreira e Alves (2014) encontraram uma relação muito estreita entre o exercício da pluriatividade com número de membros na família e o tamanho da propriedade. Os autores afirmam que famílias numerosas em propriedades pequenas tendem a serem mais pluriativas do que as famílias em propriedades maiores. Eles atribuem ao excedente de mão de obra familiar, agravado pela mecanização da agricultura e pela sazonalidade de muitas atividades agrícolas.

Essa relação entre tamanho da propriedade e número de pessoas residentes foi observada neste estudo. Analisando as Tabelas 4 e 7, das 19 famílias estudadas, oito possuem propriedades com até cinco ha, sendo explorados por três a oito 
membros na família. Ampliando a análise para um módulo fiscal, ou seja, 20 ha, que corresponde aos minifúndios, somam-se 12 famílias com número de membros variando de 3 a 8 pessoas.

É porque hoje o jovem quase não quer trabalhar na roça e a gente não tem muita terra pra trabalhar. Aí, o V. [filho] parou de estudar e foi trabalhar de pedreiro. Ele aprendeu e foi trabalhar de pedreiro. $E$ a $E$. [filha]. Nós aqui a terra é pouca, você vê que eu trabalho um pouco aqui e trabalho para os outros. Aí, decidiu trabalhar de empregado. Foi necessidade mesmo de trabalhar fora (AF4, proprietário de 2 ha e meeiro em outros 2 ha, 8 membros na família).

$\mathrm{Na}$ roça não tem o que fazer agora. O que tinha que fazer, fez. Aí tem menos serviço na fazenda e, graças a Deus, ele encontrou esse serviço aí (AF15, proprietário de 17 ha, 3 membros na família).

O excedente de mão de obra foi, dessa forma, um dos fatores que motivaram a pluriatividade conforme observado no conteúdo das falas dos agricultores entrevistados.

\section{b) A renda familiar}

Outro fator motivacional para o ingresso das famílias na pluriatividade foi a necessidade de diversificar e ampliar a renda familiar. A maior parte das famílias relatou que a renda agrícola não contribui suficientemente para a manutenção das famílias, especialmente nos períodos de entressafra. Assim, as famílias encontraram na pluriatividade uma forma de se obter renda constante que, além de aumentar o seu poder aquisitivo, sustentam suas necessidades diárias.

Ele tá lá, ele sabe que vai ter dinheiro todo mês do salário dele né? Faça chuva ou faça sol ele vai ter o seu salário e na roça as vezes seca as coisas. Quando tem alguma coisa e não colhe a tendência é baixar né? Você tem que investir hoje muito na lavoura para você ter o retorno do lucro muito pouco, muito pouco (AF7).

A gente viu que não dava só o café, tava ruim para fechar as contas. [...] Mas, é a necessidade mesmo, a necessidade que fez a gente trabalhar né? (AF18).

Schneider (2007) também explica o exercício da pluriatividade como uma forma de atender à necessidade de melhorar à renda familiar. Ele analisou a composição das rendas das famílias rurais e constatou que a renda agrícola mantém sua importância inquestionável - da mesma forma como foi observado neste estudo -, compreendendo mais da metade da renda bruta familiar anual (Tabela 4). No entanto, ele também concluiu que o papel das rendas de atividades não-agrícolas não é menos importante para a reprodução das famílias. Ele destacou, ainda, que a pluriatividade tem importância não só na geração de renda, mas também na diversificação dela, diminuindo a vulnerabilidade econômica das famílias frente às externalidades do mercado.

Assim, a diversificação da renda, bem como o esforço dos agricultores para se inserirem nos novos mercados, é uma forma de assegurar a reprodução econômica 
das famílias (GRAZIANO DA SILVA; DEL GROSSI; CAMPANHOLA, 2002; CUNHA, 2013; SILVA; MENDES, 2014).

\subsection{A RELAÇÃO ESCOLARIDADE E PLURIATIVIDADE}

Há uma distribuição relativamente equitativa entre as faixas etárias na amostra estudada, sendo nove pessoas com idade até 30 anos, sete com idade entre 31 e 40 anos e treze pessoas com idade acima de 40 anos. A média de idade dos indivíduos que possuem ocupações não agrícolas foi igual a 36,8 anos (Quadro 4).

Relacionando a faixa etária com a escolaridade, observa-se que o menor grau de instrução - até o ensino fundamental - é observado nos indivíduos com idade superior a 39 anos, com exceção do indivíduo da AF4, com 22 anos e que é ajudante de pedreiro (ocupação que não exige formação acadêmica). A maior parte dos indivíduos possui formação em nível médio (dez pessoas). Com exceção do arquiteto, as outras cinco pessoas que possuem nível superior têm formação na área de educação, exercendo a função de professora. No caso da família AF21, a mãe deixou a atividade pedagógica para cuidar dos pais idosos e, como alternativa de renda, passou a administrar o bar que a família possui na comunidade.

A maior concentração de pessoas com baixo nível de escolaridade na faixa etária acima de 40 anos pode ser explicada pela dificuldade de acesso à educação em épocas anteriores. De acordo com Peres (2011) é no meio rural que se encontra os mais baixos índices de escolaridade de adultos da sociedade brasileira, girando em torno de 3,4 anos. Para este autor, os indicadores de baixa escolaridade da população adulta residente no campo demonstram a negligência do poder público quanto ao direito de acesso e permanência na escola pela população rural.

Foi até a quarta série. Até repeti a quarta série. Na época era longe pra ir pra Bananal, estrada de chão, aquela dificuldade de ir pra estudar. Daí eu não fui, por causa da prioridade. Aí, eu fiquei em casa. (AF1, 54 anos).

Nos últimos quinze anos, o acesso ao ensino médio e superior tornou-se maior para a população rural, tanto devido ao aumento da malha de rodovias pavimentadas que facilita o deslocamento, quanto à implementação de políticas de transporte escolar e de interiorização do ensino básico e superior. São as próprias mudanças econômicas, sociais e culturais que têm ocorrido no meio rural, caracterizadas como novas ruralidades, e que se aliam às políticas de expansão do ensino médio e superior e também às exigências de formação que o mercado apresenta, que produzem as novas configurações e demandas relativas à formação acadêmica dos agricultores e, especialmente, seus filhos (ZAGO, 2016). Isso explica o fato de a maior parte dos indivíduos com nível superior na amostra estudada apresentar formação na área de educação e exercer a atividade de professora das escolas municipais e estaduais.

Ao relacionar o grau de escolaridade com o tipo de ocupação não agrícola e a renda obtida com ela, observa-se que não há proporção direta. Dos seis indivíduos que possuem nível superior, dois recebem até um salário mínimo ${ }^{4}$ mensal e dois recebem acima de dois salários mínimos. Enquanto dos treze indivíduos que possuem nível médio, seis recebem até um salário mínimo, quatro recebem até dois salários mínimos e três recebem acima de dois salários mínimos. No nível fundamental,

\footnotetext{
${ }^{4}$ O salário mínimo vigente na ocasião da pesquisa, em 2016 , era de $\mathrm{R} \$ 880,00$ (oitocentos e oitenta reais).
} 
metade recebe até um salário mínimo, os outros cinco recebem entre um e próximo de três salários mínimos.

Quadro 4 - Relação pluriatividade, grau de parentesco, idade, escolaridade e renda das famílias entrevistadas em Rio Bananal-ES, 2016

\begin{tabular}{|c|c|c|c|c|c|}
\hline Família & $\begin{array}{c}\text { Grau de } \\
\text { parentesco }\end{array}$ & Idade & $\begin{array}{c}\text { Grau de } \\
\text { escolaridade }\end{array}$ & ONA $^{*}$ & $\begin{array}{c}\text { Renda mensal } \\
\text { da ONA }\end{array}$ \\
\hline AF1 & Filho & 25 & Superior & Serviço de arquitetura & 950,00 \\
\hline AF2 & Filho & 30 & Médio & Comerciário & $1.000,00$ \\
\hline AF3 & Mãe & 43 & Médio & $\begin{array}{c}\text { Agroindústria } \\
\text { panificação }\end{array}$ & 300,00 \\
\hline \multirow{3}{*}{ AF4 } & Mãe & 49 & $\begin{array}{c}\text { Fundamental séries } \\
\text { iniciais }\end{array}$ & Artesanato - bordados & 200,00 \\
\hline & Filha & 17 & Médio incompleto & Comerciário & 380,00 \\
\hline & Filho & 22 & Fundamental & Ajudante de pedreiro & $2.000,00$ \\
\hline AF6 & Filho & 29 & Médio & Motorista de ônibus & $1.600,00$ \\
\hline \multirow{2}{*}{ AF7 } & Mãe & 39 & $\begin{array}{c}\text { Fundamental } \\
\text { incompleto }\end{array}$ & $\begin{array}{l}\text { Agroindústria } \\
\text { panificação }\end{array}$ & 450,00 \\
\hline & Pai & 43 & $\begin{array}{c}\text { Fundamental } \\
\text { incompleto }\end{array}$ & Motorista de ambulância & $2.300,00$ \\
\hline AF9 & Mãe & 44 & Pós-graduação & Professora & $1.200,00$ \\
\hline \multirow[t]{2}{*}{ AF10 } & Mãe & 39 & $\begin{array}{c}\text { Fundamental séries } \\
\text { iniciais }\end{array}$ & Faxineira & 320,00 \\
\hline & Filha & 17 & Médio & Babá & 250,00 \\
\hline \multirow[t]{2}{*}{ AF11 } & Pai & 46 & $\begin{array}{c}\text { Fundamental séries } \\
\text { iniciais }\end{array}$ & Confecção de vassouras & 600,00 \\
\hline & Filha & 18 & Superior incompleto & Recepcionista & 880,00 \\
\hline AF12 & Mãe & 53 & $\begin{array}{c}\text { Fundamental séries } \\
\text { iniciais }\end{array}$ & Agroindústria queijos & 900,00 \\
\hline \multirow{2}{*}{ AF13 } & Mãe & 41 & Superior & Professora & $2.300,00$ \\
\hline & Pai & 37 & Médio & Instrutor de autoescola & $1.000,00$ \\
\hline \multirow{2}{*}{ AF14 } & Mãe & 32 & Médio & Artesanato - bordados & 200,00 \\
\hline & Pai & 50 & Médio & Comerciário & $2.000,00$ \\
\hline AF15 & Filho & 30 & Médio & Pedreiro & $2.200,00$ \\
\hline AF16 & Mãe & 34 & Superior & $\begin{array}{l}\text { Professora e } \\
\text { agroindústria }\end{array}$ & $300,00 / 500,00$ \\
\hline \multirow[t]{2}{*}{ AF18 } & Mãe & 52 & $\begin{array}{c}\text { Fundamental séries } \\
\text { iniciais }\end{array}$ & Merendeira & $1.000,00$ \\
\hline & Pai & 50 & Médio & Fábrica de blocos & 650,00 \\
\hline \multirow{2}{*}{ AF19 } & Mãe & 35 & Superior & Professora & $2.000,00$ \\
\hline & Pai & 42 & Médio & Comércio de coco & $12.500,00$ \\
\hline AF20 & Mãe & 45 & $\begin{array}{c}\text { Fundamental séries } \\
\text { iniciais }\end{array}$ & Doméstica & 440,00 \\
\hline \multirow[b]{2}{*}{ AF21 } & Mãe & 37 & Pós-graduação & Proprietária de bar & 450,00 \\
\hline & Pai & 50 & Fundamental & Serralheria/operador & $\begin{array}{r}1.000,00 / \\
1.416,00\end{array}$ \\
\hline AF22 & Filha & 21 & Médio & Recepcionista & $1.000,00$ \\
\hline
\end{tabular}

É evidente que se situam no baixo nível de escolaridade as ocupações de pior remuneração, que seriam: doméstica, babá, faxineira e pequenas produções artesanais. Essas atividades não exigem conhecimento técnico especializado. Observa-se que os empregadores remuneram seus empregados com valores inferiores a metade do salário mínimo. O mesmo foi observado com o indivíduo da família AF4, que trabalha no comércio com uma remuneração de $\mathrm{R} \$ 380,00$ mensais para turno integral. Segundo a informante, sua mãe (ensino fundamental incompleto), essa remuneração seria para o período de experiência, denotando a falta de informação sobre os direitos trabalhistas a que a filha tem direito: "Ela tem dois meses 
que tá trabalhando lá. É experiência. No primeiro mês recebeu 380 reais. Diz que agora, depois da experiência, não sei quantos ela vai receber" (AF4).

O mesmo foi observado com as integrantes da família AF10, em que a mãe é faxineira e a filha, babá. Ambas recebem $R \$ 320,00$ e $R \$ 250,00$, respectivamente, sem atendimento aos seus direitos trabalhistas. Essas famílias se submetem à trabalhos de baixa remuneração e à informalidade basicamente por dois motivos, provavelmente: pelo desconhecimento de seus direitos trabalhistas e pela baixa escolaridade. Esta última é reforçada pela crença de que não haveria alternativa de renda para quem não estuda.

Como se diz, eu não tenho muito estudo. Meu estudo não é 'coiso'. É mesmo só faxina, mesmo, se eu conseguir, né? Se eu não tivesse a faxina, eu não tinha conseguido, porque eu não tenho estudo, meu estudo é fraco (AF10, 40 anos).

A baixa escolaridade pode influenciar na gestão dos empreendimentos familiares. A integrante da família AF12 trabalha com agroindústria de fabricação de queijos, com remuneração média mensal de $R \$ 900,00$. Ela cobra $R \$ 15,00$ por queijo, com peso médio de um quilograma. Para a fabricação de cada quilo de queijo, AF12 utiliza cerca de nove litros de leite. Já para a venda do leite in natura, AF12 cobra $R \$$ 2,50 por litro. Isso sugere que ela não percebe a diferença financeira na venda do produto processado em relação ao produto in natura. As questões relacionadas à gestão de recursos serão discutidas posteriormente.

Em contrapartida, as maiores remunerações estão associadas aos trabalhos informais como pedreiro e ajudante de pedreiro, no comércio informal de coco, além do serviço público como professora. Nota-se que o emprego como professora do estado remunera melhor que o municipal, além da estabilidade do cargo. Mas, as professoras têm remuneração similar aos ajudantes de pedreiro, dos quais não é exigido formação acadêmica. $\mathrm{O}$ arquiteto tem remuneração inferior à dos pedreiros e motoristas e de outros trabalhadores de nível médio e fundamental, pelo mesmo número de horas trabalhadas. Ainda assim, a escolha pela profissão foi influenciada pelo sentimento de realização pessoal, além da renda.

Por amor à profissão, mesmo. Porque ela gosta demais, eu sempre falei pra ela: você tá na pior profissão que existe, assim, em termos de rentabilidade mensal, não pelo fazer. E ela falava assim: mas eu gosto, eu amo! Se ela pudesse ficar o dia todo lecionando, ela ficava (AF9).

Conforme observado nos estudos de Bartalotti e Menezes-Filho (2007), a respeito da demanda no mercado de trabalho e formação profissional, o processo de escolha profissional depende não somente da situação do mercado de trabalho, mas também é fortemente influenciando por fatores subjetivos, que os autores consideram dificultar o acompanhamento de políticas públicas. Tais fatores subjetivos estariam relacionados à realização profissional e à necessidade imediata de renda, por exemplo. Isso corrobora as considerações de Schneider (2007) e de Redin (2012) de que a decisão pelo ingresso na pluriatividade, bem como o tipo de atividade não agrícola a ser desenvolvida, envolve a análise de fatores externos, como demanda de mercado, e de fatores internos, como o desejo profissional, grau de escolaridade, relações intrafamiliares e necessidade de renda.

Outros estudos, como os de Ney e Hoffmann (2009), apontam que as famílias mais pobres e com escassez de terra tendem a desenvolver atividades que exigem pouca qualificação e baixo investimento. Para esses autores, a influência da educação 
na conformação da renda não-agrícola é muito maior do que na renda agrícola, pois as melhores rendas estariam entre as pessoas ocupadas em atividades industriais e de serviços, as quais teriam mais qualificação do que aquelas ocupadas no setor primário. Os autores afirmam que a educação seria o fator responsável pelas disparidades de rendimentos do trabalho em toda a economia rural.

No entanto, outros autores afirmam depender do contexto em que se desenvolve a pesquisa, especialmente no que se refere às condições de acesso à educação e ao mercado de trabalho. Etxezarreta et al. (1995) citado por Schneider, Ferreira e Alves (2014), afirma que não se pode estabelecer nenhuma relação causal direta entre o nível de escolaridade e maiores rendimentos. Além da escolaridade, há a necessidade de se considerar as características do ambiente social e econômico em que os agricultores estão inseridos, "para não incorrer em equívoco ou precipitação e concluir apressadamente que há uma relação linear entre baixos níveis de instrução e renda per capita baixa" (SCHNEIDER; FERREIRA; ALVES, 2014, p. 13).

\subsection{O PROCESSO DA GESTÃO DE RECURSOS DA PROPRIEDADE E DA FAMÍLIA}

A questão da gestão da unidade familiar se torna importante no contexto da agricultura. Em todas as famílias participantes da pesquisa foi observado o desconhecimento em administração dos recursos. Os entrevistados não souberam informar com precisão qual a área ocupada com a cultura ou o número de plantas, nem mesmo a renda bruta familiar; não consideraram a renda indireta gerada pela produção de subsistência para o cálculo da renda total; não conhecem os custos de produção das atividades agrícolas desenvolvidas na propriedade; não computam a mão de obra familiar na construção do custo de produção e, muitas vezes, não souberam informar a renda obtida na ocupação não agrícola desempenhada por outros membros da família. As mulheres que exercem a produção artesanal sequer souberam informar a renda aproximada obtida com a venda dos produtos.

Ao ser questionado qual a área plantada com café, AF1, agricultor de 54 anos, não soube informar: "Deve ter o quê? Não dá dois alqueires ${ }^{5}$ [de café]. [...] Dá não. Coloca meio alqueire, pode colocar". Quanto a produção, a situação foi a mesma: "Não sei como colocar. Este ano deu bem menos. O ano passado deu umas 80 sacas. Este ano não deu nem um terço. Fica difícil colocar". A esposa completou: "Umas 30 , deu este ano, né? [...] Não, coloca menos. Umas 27, vou colocar 27 [sacas de café]".

A produtora de pães, bolos e doces AF7 considera difícil calcular a renda com a produção dos quitutes, pois depende de encomenda, não sendo uma renda contínua e fixa.

É difícil calcular, tipo assim, não é sempre que eu tenho encomenda. Vamos supor uma semana que eu tenho um casamento, dá pra mim tirar bem, mas tem semana que eu quase não tenho encomenda, entendeu? Esta semana mesmo acho que só fiz duzentos reais. Então, de uma semana para outra varia muito, de um mês para o outro. Já tem época em que você pega, igual para o dia das mães mesmo, eu fiquei até meia noite em pé fazendo coisas, porque não dava conta, entendeu? Aí varia muito por isso [...]. Teve mês no dia das mães mesmo, eu tirei líquido quinhentos e poucos reais por semana de massas

\footnotetext{
${ }^{5}$ No Estado do Espírito Santo o alqueire de referência é o geométrico, que corresponde a 4,84 ha (BRASIL, 2011).
} 
e doces. Então, depende. Por mês, pode colocar assim, uns quatrocentos a quatrocentos e cinquenta reais, chega (AF7).

Outras particularidades são observadas, como já citado o caso da produtora de queijos AF12. Além de não saber informar a produção agropecuária da família, também não sabia estimar a renda com a venda de leite in natura nem da produção de queijos. Para se estimar a renda obtida com a venda de queijos, os autores se basearam na quantidade de unidades vendidas por semana, multiplicando-se pelo preço cobrado pela produtora. Ao analisar a renda oriunda do processamento do leite, chegou-se à conclusão de que a produtora não valoriza suficientemente a transformação. Observa-se, portanto, que cálculos simples de custo de produção são negligenciados pelos produtores que não percebem quando têm prejuízos ou lucros em suas atividades produtivas.

Analisando-se as entrevistas, foi possível saber que a maior parte dos indivíduos (21) com ocupações não agrícolas utiliza a renda não agrícola para atender às despesas familiares. Estudos demonstram que renda de atividades não agrícolas contribui para o sustento da família e para suprir as ineficiências na atividade agrícola (SCHNEIDER, 2010; VIRGOLIN; HILLING; FROEHLICH, 2015), indicando a importância do papel da pluriatividade na própria manutenção dos agricultores familiares no campo.

No entanto, a deficiência na gestão dos recursos pode comprometer os rendimentos da família. De acordo com Favaro e Nogueira (2017), grande parte dos agricultores não possui o hábito de anotar as entradas e as saídas de recursos e, mesmo os que o fazem, não utilizam das informações para a tomada de decisões, devido ao pouco conhecimento de gestão financeira.

Kimura (1998) citado por Reichert e Gomes (2013) afirma que a atividade agrícola está exposta a riscos de produção, operacionais, financeiros e de mercado. Segundo este autor, o planejamento e gerenciamento podem controlar ou minimizar os riscos de produção, operacionais e financeiros. No entanto, os riscos de mercado podem inviabilizar o processo de produção, devido à flutuação de preços, não sendo possível ter um controle sobre ele. O excesso de oferta ou a falta de demanda seriam os principais fatores de risco de mercado.

Para Redin (2013), os agricultores familiares têm dificuldade de gerir seus bens e controlar os custos reais de seus investimentos, mesmo quando têm noção do pagamento de juros ou dispendendo altos valores. O autor cita que há uma necessidade de se instituir um controle mais rigoroso das ações financeiras praticadas pelas famílias, o que contribuiria para as tomadas de decisão futuras. Ele atribui essa negligência por parte do agricultor ao não domínio administrativo em decorrência da baixa formação escolar.

Reichert e Gomes (2013) afirmam, portanto, que nem sempre as decisões são fáceis de serem tomadas, pois os agricultores necessitam de mais conhecimentos sobre gestão. A tarefa de decidir se torna difícil e complexa quando os agricultores não dispõem de todas as informações no momento de tomada de decisão. Os autores deixam claro que a agricultura familiar não segue a lógica da racionalidade econômica da maximização de lucros. Aspectos sociais, ambientais, culturais, éticos e ideológicos são considerados no momento da tomada de decisão. O conhecimento empírico dos agricultores também deve ser considerado, haja vista que eles tomam as decisões a partir da totalidade do sistema, valendo-se do seu bom senso, da intuição e de regras percebidas ou estipuladas por eles.

Dessa forma, o problema da gestão da propriedade familiar deve ser considerado nas políticas públicas e pelos técnicos que acompanham esses agricultores. A orientação na elaboração do custo de produção e no processo de 
gestão de recursos humanos e materiais deve fazer parte do dia a dia da extensão rural, seja ela praticada pelos órgãos oficiais de Assistência Técnica e Extensão Rural (ATER), seja pelos setores de representação da agricultura familiar, como o STRRB.

A gestão adequada da produção agropecuária, aliada à pluriatividade, pode contribuir para a geração de emprego e renda para a agricultura familiar, para a manutenção das famílias no campo e para o seu crescimento econômico.

\section{CONSIDERAÇÕES FINAIS}

Com a análise dos dados empíricos foi possível concluir que a pluriatividade foi um importante fator de geração de emprego e renda para as famílias estudadas.

Mesmo para as famílias que apresentaram baixa proporção de renda não agrícola no montante total da renda familiar, a pluriatividade representou maior independência financeira da família em relação aos rendimentos agropecuários. Pelo fato de as principais culturas agrícolas desenvolvidas pelas famílias estudadas serem de safras sazonais, como o café e a pimenta-do-reino, a pluriatividade serviu como uma fonte contínua e fixa de renda, para a maioria das famílias. Especialmente no período de crise hídrica que a região enfrentou, a queda da produção comprometeu a renda familiar, mas as atividades não agrícolas tornaram-nas flexíveis em sua adaptação à crise por diversificar suas fontes de renda.

Conclui-se que os principais fatores que influenciaram no ingresso das famílias na pluriatividade foram as questões relacionadas à renda, já mencionadas, e à empregabilidade da mão de obra ociosa. Esta última faz referência ao reduzido tamanho das propriedades que não dispõem de espaço suficiente para empregar toda a mão de obra familiar, a qual se torna excedente. O uso de tecnologias reduz a necessidade de mão de obra que, aliado à concentração sazonal dos tratos culturais nas atividades agrícolas, gera ociosidade da mão de obra em parte do ano. Esses fatores contribuem para a busca de outras formas de ocupação e renda pelos membros das famílias.

Conclui-se que a proximidade da Comunidade Córrego Primavera do centro urbano de Rio Bananal pode ter influenciado no predomínio da pluriatividade intersetorial, especialmente em serviços na zona urbana.

Também foi possível concluir que as famílias, em geral, desconhecem os custos de produção e os processos administrativos, comprometendo a eficiência na gestão dos recursos humanos e materiais da família.

Não se pretendeu generalizar para todos os contextos da agricultura familiar as conclusões deste trabalho, mas compreender a realidade das famílias estudadas e, a partir daí tecer considerações que possam contribuir para novos estudos. Assim, considera-se que a pesquisa sobre a pluriatividade no município de Rio Bananal e região deve ser estendida, objetivando o estudo comparativo das famílias pluriativas com as famílias monoativas, buscando o entendimento das relações produtivas e do processo de decisão dos agricultores diante das externalidades ambientais, sociais e de mercado. Também devem ser estudadas outras comunidades com o objetivo de se verificar o quanto a proximidade do centro urbano influencia no predomínio de algum tipo de pluriatividade naquela região. Os resultados desses estudos podem contribuir para a orientação de políticas de geração de emprego e renda no espaço rural da Microrregião Rio Doce, baseado nos contextos socioeconômicos, culturais e estruturais em que as famílias agricultoras se inserem.

\section{REFERÊNCIAS}

BARDIN, L. Análise de conteúdo. Lisboa: Edições 70, 1977. 
BARTALOTTI, O.; MENEZES-FILHO, N. A relação entre o desempenho da carreira no mercado de trabalho e a escolha profissional dos jovens. Economia Aplicada, São Paulo, v.11, n.4, p.487-505, out./dez.2007.

BRASIL. Lei n. 11.326, de 24 de julho de 2006. Estabelece as diretrizes para a formulação da Política Nacional da Agricultura Familiar e Empreendimentos Familiares Rurais. Diário Oficial União, Poder Executivo, Brasília, DF, 25 jul. 2006. Seção 1, p.1.

BRASIL. ITR 2011: Manual de Preenchimento da Declaração. Brasília: Secretaria da Receita Federal, 2011. Disponível em: http://idg.receita.fazenda.gov.br/orientacao/tributaria/ declaracoes-e-demonstrativos/ditr-declaracao-do-imposto-sobre-a-propriedadeterritorial-rural/programa-gerador-da-declaracao-pgd-ditr-perguntas-e-respostas-ebase-legal/2011/manualdepreenchimentoditr2011.pdf. Acesso em: 05 dez. 2018.

BRASIL. Perfil territorial - Juparanã-ES. Brasília: Ministério do Desenvolvimento Agrário, 2015. Disponível em: http://sit.mda.gov.br/download/caderno/caderno_territorial_108_Juparan\%C3\%83\%C 2\%A3\%20-\%20ES.pdf. Acesso em: 29 out. $201 \overline{6}$.

CUNHA, A.S. Agricultura familiar e suas estratégias de resistência na Campanha Gaúcha: o caso do Rincão dos Saldanhas e do Cerro da Jaguatirica - Manoel Viana/RS. 2013. 133f. Dissertação (Mestrado em Geografia) - Programa de PósGraduação em Geografia e Geociências, Universidade Federal de Santa Maria.

DEWES, J.O. Amostragem em bola de neve e respondent-driven sampling: uma descrição dos métodos. 2013. 53f. Monografia (Bacharelado em Estatística) - Curso de Estatística - Bacharelado, Universidade Federal do Rio Grande do Sul.

ESPÍRITO SANTO. Seca no ES: prejuízo de mais de $r \$ 3,6$ bilhões na agricultura. Portal do governo do estado do Espírito Santo. Notícias, Vitória, 19 set. 2016. Disponível em: http://www.es.gov.br/noticias/182678/seca-no-es-prejuizo-de-maisde-r-36-bilhoes-na-agricultura.htms_sh. Acesso em: 02 nov. 2016.

FAVARO, K.J.; NOGUEIRA, D.R. Produtor rural familiar: um estudo sobre a adesão aos controles de custos na cidade de Londrina-PR. Extensão Rural, Santa Maria, v.24, n.4, p.102-117, out./dez. 2017.

FONTANELLA, B.J.B. et al. Amostragem em pesquisas qualitativas: proposta de procedimentos para constatar saturação teórica. Cadernos de Saúde Pública, Rio de Janeiro, v.27, n.2, p.389-394, fev. 2011.

GIANNAKIS, E.; EFSTRATOGLOU, S.; ANTONIADES, A. Off-farm employment and economic crisis: evidence from Cyprus. Agriculture, Basel, Switzerland, v.8; n.41, 2018. Disponível em: https://www.mdpi.com/2077-0472/8/3/41/pdf. Acesso em: 05 dez. 2018.

IBGE. Censo agropecuário 2006. Agricultura Familiar: Primeiros Resultados. Rio de Janeiro: IBGE, 2006. 267p. 
IBGE. Cidades@. Rio Bananal. 2010. Disponível em: http://www.cidades.ibge.gov.br/xtras/perfil.php?lang=\&codmun=320435\&search=espi rito-santo|rio-bananal. Acesso em: 26 fev. 2016.

IBGE. Produção da pecuária municipal 2015. Rio de Janeiro: IBGE, 2015. v.43. Disponível em: http://cod.ibge.gov.br/1KCYP. Acesso em: 30 out. 2016.

INCAPER. Programa de Assistência Técnica e Extensão Rural PROATER 2011 2013: Rio Bananal. Secretaria da Agricultura, Abastecimento, Aquicultura e Pesca. Governo do Estado do Espírito Santo. 2011. Disponível em: https://incaper.es.gov.br/media/incaper/proater/municipios/Nordeste/Rio_Bananal.pdf . Acesso em: 28 out. 2016.

INCAPER. Acompanhamento semanal de preços recebidos pelos produtores: SISPREÇO - Outubro/2016. Secretaria da Agricultura, Abastecimento, Aquicultura e Pesca. Governo do Estado do Espírito Santo. s.d. Disponível em: https://incaper.es.gov.br/Media/incaper /PDF/sispreco2016/10_Outubro-1.pdf. Acesso em: 23 mar. 2017.

INCRA. Classificação dos imóveis rurais. s. d. Disponível em: http://www.incra.gov.br/tamanho-propriedades-rurais. Acesso em: 10 nov. 2016.

MUSSATO, R.M.; SANTOS, R.A. Pluriatividade na agricultura familiar do munícipio de Itapejara d' Oeste-PR. In: CONGRESSO BRASILEIRO DE GEÓGRAFOS, 7., 2014, Vitória, ES. Anais... Vitória: ABG, 2014.

NEY; M.G.; HOFFMANN, R. Educação, concentração fundiária e desigualdade de rendimentos no meio rural brasileiro. Revista de Economia e Sociologia Rural, Brasília, v.47, n.01, p.147-182, jan./mar. 2009.

PERES, M.A. de C. Velhice e analfabetismo, uma relação paradoxal: a exclusão educacional em contextos rurais da região Nordeste. Revista Sociedade e Estado, Brasília, v.26, n.3, p.631-661, set./dez. 2011.

REDIN, E. Estratégias de reprodução na agricultura familiar - um campo em permanente construção. Acta Geográfica, Boa Vista, v.6, n.13, p.155-173, set./dez. 2012. Disponível em: https://revista.ufrr.br/actageo/article/view/521/912. Acesso em 23 mar. 2017.

REDIN, E. Muito além da produção e comercialização: dificuldades e limitações da agricultura familiar. Perspectivas em Políticas Públicas, Belo Horizonte, v.6, n.12, p.111-151, jul./dez. 2013. Disponível em: http://revista.uemg.br/index.php/revistappp/article/view/872/566. Acesso em 23 mar. 2017.

REICHERT, L.J.; GOMES, M.C. O processo administrativo e a tomada de decisão de agricultores familiares em transição agroecológica. Revista de la Facultad de Agronomía, La Plata, v.112, n.2, p.105-113, 2013.

SCHNEIDER, S. A importância da pluriatividade para as políticas públicas no Brasil. Revista Política Agrícola, Brasília, v.16, n.3, p.15-34, 2007. 
SCHNEIDER, S. A pluriatividade na agricultura familiar. 2.ed. Porto Alegre: Editora da UFRGS, 2010.

SCHNEIDER, S.; CONTERATO, M.A. Transformações agrárias, tipos de pluriatividade e desenvolvimento rural: considerações a partir do Brasil. In: NEIMAN, G.; CRAVIOTTI, C. (Org.). Entre el Campo y la Ciudad: Desafíos y estrategias de la pluriactividad en el agro. Buenos Aires: Ciccus, 2006.

SCHNEIDER, S.; FERREIRA, B.; ALVES, F. (Orgs.). Aspectos multidimensionais da agricultura brasileira: diferentes visões do Censo Agropecuário 2006. Brasília: Ipea, 2014.

SILVA, J.F.G. O novo rural brasileiro. Nova Economia, Belo horizonte. v. 7, n.1, p. 43-81, mai. 1997.

SILVA, J.F.G.; DEL GROSSI, M.; CAMPANHOLA, C. O que há de realmente novo no rural brasileiro. Cadernos de Ciência \& Tecnologia, Brasília, v.19, n.1, p. 37-67, jan./abr. 2002.

SILVA, J.M.; MENDES, E. de P.P. Agricultores familiares e reprodução social: as comunidades Cruzeiros dos Martírios e Paulistas no município de Catalão (GO). In: NEVES, A.F. et al. (Org.). Coletânea interdisciplinar em pesquisa, pós-graduação e inovação. São Paulo: Blucher, 2014. p. 241-255. v 1.

VIRGOLIN, I.W.C.; HILLING, C.; FROEHLICH, J.M. Um estudo sobre os sentidos do trabalho para os agricultores familiares a partir da pluriatividade. Extensão Rural, Santa Maria, v.22, n.4, p.116-135, out./dez. 2015.

WANDERLEY, M. de N.B. A emergência de uma nova ruralidade nas sociedades modernas avançadas: o "rural" como espaço singular e ator coletivo. Estudos Sociedade e Agricultura, Rio de Janeiro, v.8, n.2, p.87-145, out. 2000.

ZAGO, N. Migração rural-urbana, juventude e ensino superior. Revista Brasileira de Educação, Rio de Janeiro, v.21 n.64, p.61-78, jan./mar. 2016. 